\title{
Koebner phenomenon induced by ear loops of the face mask
}

Anca E. Chiriac ${ }^{1}$, Anca Chiriac ${ }^{2}$, and Uwe Wollina ${ }^{3}$

${ }^{1}$ Affiliation not available

${ }^{2}$ Apollonia University Iasi, Strada Muzicii nr 2, Iasi-700399, Romania

${ }^{3}$ Academic Teaching Hospital Dresden-Friedrichstadt

October 12, 2020

\begin{abstract}
We present a case of koebner phenomenon induced by friction, caused by tightness of ear loops of face mask, used as protective measure against spreading COVID-19 infection.
\end{abstract}

\section{Hosted file}

Koebner phenomenon induced by ear loops of the face mask copy.pdf available at https: //authorea.com/users/366267/articles/486346-koebner-phenomenon-induced-by-ear-loopsof-the-face-mask

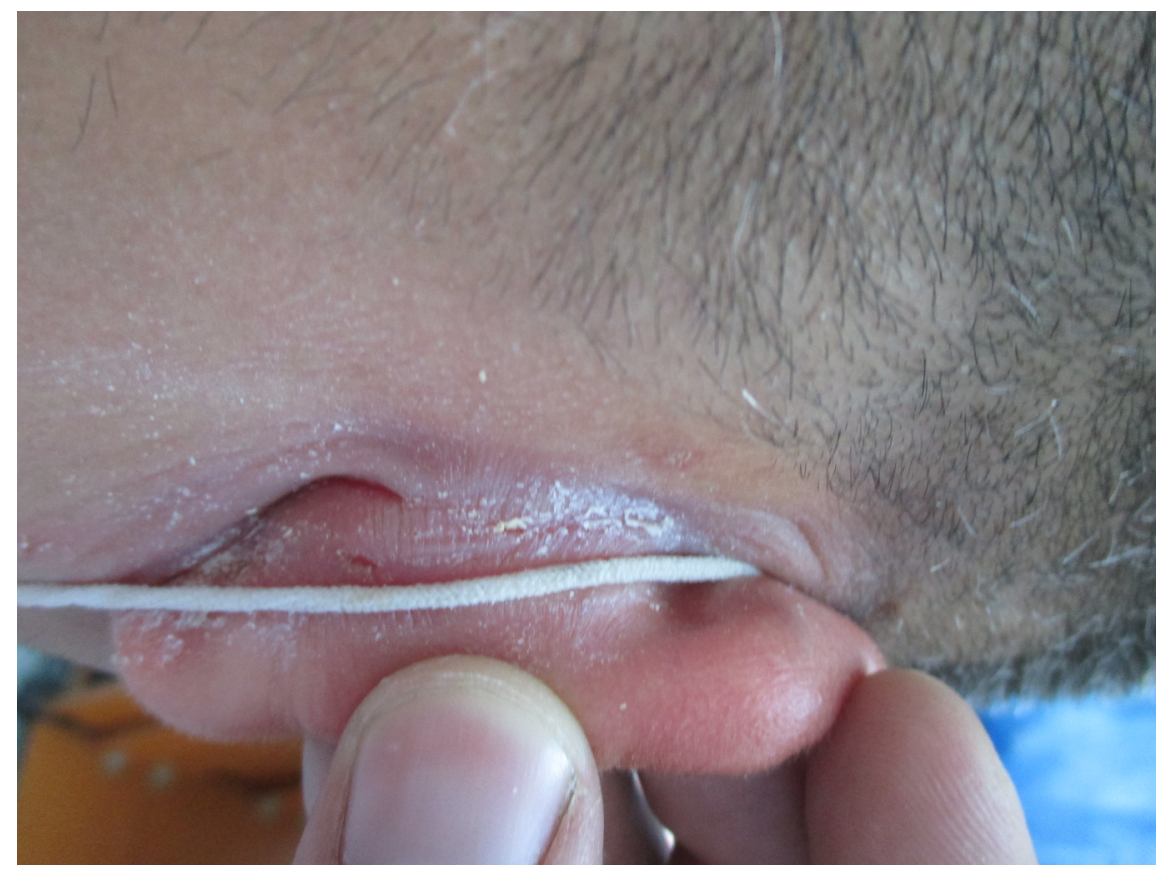

